AperTO - Archivio Istituzionale Open Access dell'Università di Torino

\title{
Ambiguity and partisan business Cycles
}

\section{This is the author's manuscript}

Original Citation:

\section{Availability:}

This version is available http://hdl.handle.net/2318/7052

since

Publisher:

JCB Mohr:Wilhelmstrasse 18, D-72074 Tuebingen Germany:011 497071 9230, EMAlL: info@mohr.de,

Terms of use:

Open Access

Anyone can freely access the full text of works made available as "Open Access". Works made available under a Creative Commons license can be used according to the terms and conditions of said license. Use of all other works requires consent of the right holder (author or publisher) if not exempted from copyright protection by the applicable law. 


\section{Ambiguity and Partisan Business Cycles}

\section{Anna Maffioletti and Michele Santoni*}

We introduce ambiguity (Knightian uncertainty) into a stripped-down version of Alesina's (1987) partisan model of the business cycle. We show that, if the private sector's subjective expectations of future events are ambiguous, there is the possibility of a political business cycle, even when the parties running for the election have similar preferences for inflation and unemployment. In particular, if inflation is perceived as a loss, then the larger the fraction of the population that is ambiguity-prone (-averse), the larger is the postelection boom (slump), with unemployment then returning back to its natural level. We also show that, for given parties' preferences, ambiguity proneness (aversion) implies smaller (larger) fluctuations in the unemployment around its natural level when the right-wing party wins the elections. (JEL: D81, E32, E42; Keywords: Ambiguity, Ellsberg's paradox, Partisan theory of the business cycle, Unemployment)

\section{Introduction}

One of the novelties of European politics in the 1990s seems to be the emergence of a "new free-market left" that often talks the same language of the liberal right in economics. Notable examples include New Labour in Britain and the Olive Tree coalition in Italy. Both announced their commitment towards antiinflation policies and privatization, and took steps to make it credible (as, e.g., the instrument independence given to the Bank of England in the aftermath of the 1997 U.K. election). These episodes seem to suggest a convergence of economic-policy objectives between the new free-market left and the liberal right in Europe.

This convergence in objectives has important implications for the way many economists perceive the influence of politics on the business cycles. A large part of the literature considers how an incumbent government can use monetary policy for exploiting, temporarily or permanently, an inflation-unemployment trade-off. One popular model is the rational parti-

* We would like to thank an anonymous referee and one of the editors of this Journal for helpful comments, and John Hey for useful discussions. An early version of this paper was presented at the 1998 Royal Economic Society conference (Warwick), and at seminars in Aberystwyth, Hull, and Torino. We gratefully acknowledge financial support and hospitality from ICER Torino. We are responsible for any remaining errors. 
san theory of Alesina (1987), which builds on Hibbs (1977). Partisan politicians have different objective functions, with left-wing politicians being more concerned about the welfare loss of unemployment than right-wing politicians. If wage-setters have rational expectations and sign noncontingent nominal wage contracts at discrete intervals, occurring just before and after the elections, Alesina shows that uncertainty about the election outcome generates higher (lower) than expected inflation if the left-wing (right-wing) party wins, which implies a postelection boom (slump). After the election has occurred, wage-setters correctly revise their expectations, and unemployment returns to its natural rate, such that the time-consistent inflation rate is higher (lower) under the left (right).

Alesina et al. (1997, ch. 6) present empirical evidence from a panel of OECD countries for the years 1960-1993 in favor of this theory, "particularly for countries with a two-party system or with clearly identifiable right and left coalitions." Persson and Tabellini (1999, pp. 1404, 1416) also argue that postelection partisan cycles in real variables and inflation have been one of the basic stylized facts of postwar monetary policy in the above countries $^{1}$. However, casual observations seem to suggest that the rational partisan theory is less equipped to explain recent episodes. For instance, in 1996 the election of a new conservative government in Spain was associated with a postelection boom (albeit small), whereas that of a new center-left government in Italy was associated with a postelection slump ${ }^{2}$. Moreover, if, between competing parties, there is convergence in objectives for inflation and unemployment, the rational partisan theory predicts that the size of the cycle should be reduced and eventually eliminated ${ }^{3}$. Finally, this theory does not allow for the persistence of unemployment, which seems a well-established empirical fact, at least in Europe ${ }^{4}$.

In order to tackle some of these empirical puzzles, the present paper introduces the concept of Knightian uncertainty or ambiguity into a strippeddown version of Alesina $(1987)^{5}$. In Alesina (1987), the probability distribution over unknown electoral outcomes is exogenously given and common knowledge. The present paper allows for decision-makers (namely, wagesetters) to face Knightian uncertainty (namely, unknown probabilities) over

1 See Drazen (2000, pp. 260-268) for a critical assessment of the evidence.

2 For Spain, the difference between the average GDP growth rate in the first six quarters after the election and in the first six quarters before the election was 0.38 ; for Italy, the same difference was -1.69 .

3 Alesina et al. (1997, pp. 261-262) dispute the claim that convergence in objectives has been taking place.

4 Alogouskofis et al. (1992) generate unemployment persistence by introducing insideroutsider features in the rational partisan model; see also Jonsson (1997).

5 Note that our concept of ambiguity differs from the one used by Alesina and Cukierman (1990); the latter refers to the risk associated with the policymaker type, rather than to uncertainty about the state of the world that will prevail. 
electoral outcomes, rather than a risky choice where the full probability distribution is known (see Ellsberg, 1961). The main result of the paper is that the presence of ambiguity-averse or -prone wage-setters, by biasing inflation expectations relative to rational expectations, can change, both qualitatively and quantitatively, the nature of partisan business cycles in predictable ways. In particular, under certain conditions, there is the possibility both that victory by the right can induce a postelection boom (see Proposition 1 below) and that partisan business cycles occur even with full policy convergence (see Proposition 3 below).

The use of Knightian uncertainty is motivated by the belief that a political election can often be considered as a genuinely ambiguous event. In general, there is decision-making under ambiguity, when the information possessed by the decision-makers on the occurrence of some event is scarce, irrelevant, or conflicting. If this is the case, the decision-makers may not be able to form subjective probabilities on the occurrence of such an event. In the case of a political election, polls may give an estimate of a party's probability of victory to wage-setters forming inflation expectations, but they are often imprecise, and may fail to predict the correct results, even on the election eve (see Jowell et al., 1993, for the 1992 U.K. election) ${ }^{6}$. Ambiguity can be especially relevant when the parties running for election are new (e.g., Forza Italia and Ulivo in Italy) or have new leaderships (e.g., New Labour in the U.K.), which may increase the fraction of the undecided in preelection polls ${ }^{7}$. Moreover, when the environment is new, we may expect individuals to experience difficulties in assessing probabilities over events, and to feel unconfident about having a complete description of all the possible states of the world.

In order to model ambiguity, the present paper adopts Einhorn and Hogarth's (1985) "anchoring and adjustment" model (see below). The basic idea is that, when assessing probabilities, wage-setters apply a twofold process: firstly, they anchor their judgmental probability to some commonknowledge probability estimate of the likelihood of victory for one of the two parties (here, the mean value of a uniform probability distribution over the unit interval, implying an anchor probability value of $p=0.5$ ). Second, they adjust this anchor value to reflect the ambiguity present in the

6 Bohm and Sonnergard (1999, pp. 205-208) give further references about polls' lack of prediction accuracy.

7 As Ellsberg (1961, pp. 660-661) puts it, "Ambiguity is a subjective variable, but it should be possible to identify 'objectively' some situations likely to present high ambiguity, by noting situations where available information is scanty or obviously unreliable or highly conflicting; or where expressed expectations of different individuals differ widely; or where expressed confidence in estimates tends to be low....Thus as compared with the effects of...well-known random processes (like coin-flipping or roulette)... the performance of a new President, or the tactics of an unfamiliar opponent are all likely to appear ambiguous." (Emphasis added.) 
election. As long as uncertainty lowers the confidence in their assessment of the probability, wage-setters simulate probability values different from the anchor: ambiguity reaction is then captured by introducing nonlinear decision weights instead of probabilities ${ }^{8}$. The direction and size of these simulations, or the shape of the weighting function, may differ according to the individual attitudes: both rational and nonrational wage-setters may operate in the economy, and the latter can be either uncertainty-averse or -prone (see below) ${ }^{9}$. Therefore, the use of such a model will allow us to make a direct comparison between the results of our paper and Alesina's (1987).

In the current paper, we shall also assume that the wage-setters perceive inflation as a loss, thus ex ante preferring the victory of the low-inflation, right-wing party. As Cukierman and Lippi (1999) and Grüner and Hefeker (1999) point out in the literature on unionized labor markets and monetary policy, union members may dislike inflation as long as their pensions and other savings are not fully indexed or not indexed at all. This may be particularly relevant for countries like Italy, where more than half of the total members of the two leading confederations are pensioners and where, from 1992 on, index linking of benefits to real wages has been abolished and index linking to CPI inflation has been reduced ${ }^{10}$.

The plan of the paper is as follows. Section 2 introduces ambiguity into a stripped-down version of Alesina (1987). Section 3 studies the issue of convergence in objectives. Section 4 concludes with final remarks.

\section{The Model}

\subsection{A Standard Model}

There are three agents: the private sector and the left-wing $(L)$ and rightwing $(R)$ parties. The timing of events is as follows. Before the election, at

8 Other theories of ambiguity reaction use decision weights instead of probabilities; see Schmeidler (1989), Tversky and Kanheman (1992), and Tversky and Wakker (1995). According to these models, a single prospect $(x A ; 0 B)$ (i.e., prize $x$ is obtained if event $A$ occurs; nothing is obtained if $B$ occurs) is evaluated by $w(A) v(x)+w(B) v(0)$, where the decision weights $w(A)$ and $w(B)$ (i.e., the psychological likelihood assigned to the events $A$ and $B$ ) may not be additive: if $A$ and $B$ are two disjoint events, $w(A)+w(B)$ may differ from unity.

9 A growing amount of experimental evidence shows that individuals' attitude toward ambiguity depends on whether they perceive the outcome as a gain or as a loss, and on the level of probability; see for example Hogarth and Einhorn (1990), Tversky and Fox (1995), Di Mauro and Maffioletti, (1996), and Wu and Gonzalez (1999). Camerer and Weber (1992) survey the earlier experimental literature on uncertainty reaction.

10 Chiarini (1999) argues that pensioners' political influence on the Italian trade-union confederation had increased in the 1990s and shows that it significantly accounts for part of the observed real wage moderation during this period. 
time $t=0$, the private sector forms a subjective inflation expectation for the subsequent period, and workers sign noncontingent nominal-wage contracts for $t=1$ on the basis of this expectation ${ }^{11}$. The private sector is fully aware of the preferences of the two parties towards inflation and unemployment. However, it does not know with certainty which party is going to win the election. Then, the election takes place, and the winning party stays in power for two periods. Subsequently, at $t=1$, the new government implements its desired inflation (monetary) policy for its first period of tenure, the private sector forms a subjective inflation expectation for the second period, and new nominal-wage contracts are signed for $t=2$. Finally, at $t=2$, the incumbent government implements its desired inflation (monetary) policy for that period. Therefore, we consider the subgame-perfect equilibrium of the one-shot, two-stage inflation policy game with one-period predetermined nominal wages.

The economy is described by a short-run Phillips curve

$$
U_{t}=U^{N}+a\left(\Pi_{t}^{E}-\Pi_{t}\right),
$$

where $a>0$ is a constant supply response parameter, and $U_{t}, U^{N}, \Pi_{t}, \Pi_{t}^{E}$ are the actual and natural rates of unemployment, the actual inflation rate, and the private sector's subjective expectation of the inflation rate for time $t$, formed at time $t-1$, respectively ${ }^{12}$. We model expected inflation below. Each party aims at minimizing the following static loss function:

$$
L_{t}^{i}=\left(\Pi_{t}\right)^{2}+b^{i}\left(U_{t}-U^{*}\right)
$$

where $t=\{1,2\}, i=\{\underline{L}, R\}$, and $b^{L}>b^{R}>0$. That is, party $L$ cares more than party $R$ about the welfare costs of unemployment. For simplicity, both parties have the same inflation and unemployment targets: zero inflation and $U^{*}<U^{N}$ respectively. The unemployment target is below its natural rate, because of distortions in the economy, which politicians feel unable to eliminate directly by using supply-side policies ${ }^{13}$. Clearly, this assumption implies that the discretionary equilibrium will be characterized by a positive inflation bias, with respect to the second-best optimal precommitted equilibrium of zero inflation.

We solve the model by backward induction. Taking inflation expectations as given, the winning party minimizes the loss function (2) subject to the short-run Phillips curve (1), which yields the following time-consistent dis-

11 Drazen (2000, pp. 254-255) summarizes the pitfalls of such an assumption; see also section 3 below.

12 The short-run Phillips curve is independent of exogenous shocks, since our focus is on policy-induced cycles.

$13 U^{*}$ can be interpreted as the Walrasian natural rate of unemployment. 
cretionary inflation rate:

$$
\Pi_{t}^{i}=\frac{a b^{i}}{2}, \quad i=\{L, R\} .
$$

Of course, our assumption that the loss function (2) is linear in unemployment deviations from the target implies a constant inflation policy: the policy rule (3) is independent of the private sector's inflation expectations ${ }^{14}$. Moreover, given that $U^{*}<U^{N}$, and that there is no possibility of precommitment, (3) represents the standard inflation bias.

\subsection{Introducing Ambiguity}

To this point, the model is standard. Our departure from previous models of partisan political business cycles consists in assuming that the decisionmakers face ambiguity. Before the election has occurred, the private sector's decision-makers form their inflation expectation for the next period, knowing the inflation policy rule (3) that each party will implement in the case of an election victory, but being uncertain about the election outcome.

We assume that the decision-makers prefer low to high inflation, irrespective of the actual rate of unemployment: their preferred election outcome is party $R$ 's victory. In other words, we assume that inflation is perceived as a loss (even if it was perfectly anticipated). Therefore, the decision-makers would like inflation to be as low as possible ${ }^{15}$. This may be the case if the decision-makers are composed of many identical (except for their subjective perception of ambiguity; see below), uncoordinated, insider-dominated trade unions, who dislike inflation because they care about the real wages, nonindexed benefits, and pensions of their employed and retired membership; see Cukierman and Lippi (1999) and Grüner and Hefeker (1999) ${ }^{16}$. Alternatively, the private sector may be composed of the financial markets that dislike inflation: uncoordinated wage-setters sign their nominal-wage contracts following the inflation forecast of the markets.

We allow for different subjective reactions to ambiguity. In particular, we assume that a fraction $1-k$ of the decision-makers are ambiguity-neutral -

14 This follows Alesina (1987). In an appendix, available from the authors on request, we show that our results are qualitatively unchanged if the loss function is quadratic in unemployment deviations from target instead.

15 Recent studies on the perceived costs of inflation conclude that "people find inflation costly, and are willing to undergo a recession to get rid of price increases" (see Di Tella et al., 2001, for econometric evidence) even if this means "that millions more people would be unemployed" (see Shiller, 1996, p. 19, for survey evidence).

16 These papers, however, assume explicitly that the typical union's linear-quadratic loss function depends negatively on the real wage and positively on both unemployment and inflation. 
that is, they have rational expectations - and that the remaining fraction $k$ are either ambiguity-averse or -prone; see below. The expected inflation rate for time $t$ is

$$
\Pi_{t}^{E}=(1-k)\left[p^{L} \Pi_{t}^{L}+\left(1-p^{L}\right) \Pi_{t}^{R}\right]+k\left[s\left(p^{L}\right) \Pi_{t}^{L}+s\left(1-p^{L}\right) \Pi_{t}^{R}\right] .
$$

Expected inflation is a weighted arithmetic average of the subjective inflation expectations of the two types of decision-makers. These subjective expectations depend on the time-consistent inflation rates of the two parties, and on the common-knowledge probability assigned to the victory of party $L, p^{L}$, which represents the anchor value of the probability associated with the worst outcome (i.e., that the high-inflation $L$ party wins the election). Such an anchor value is established in relation to the information set before the election, which may include electoral polls. It is convenient to think of $p^{L}$ as the mean of the probability distribution of the electoral outcome, i.e., as the probability assigned to party $L$ 's victory when the decision-makers have rational expectations. In order to simplify the analysis, we assume that $p^{L}$ is uniformly distributed over the range $[0,1]$, so that its mean is equal to onehalf before the election takes place. After the election has taken place, the decision-makers know with certainty who is in power, and this probability anchor is revised upward (downward) to unity (zero) if party $L$ is in (out of) office.

If the anchor probability value is then adjusted upward or downward depending on the decision-makers' subjective attitude towards ambiguity, then according to our model $s\left(p^{L}\right)$ will represent the weight associated to party $L$ 's victory, or the anchor, while $s\left(1-p^{L}\right)$ will be that associated to the complementary event of party $R$ 's victory.

Therefore, consistently with Einhorn and Hogarth (1985), we assume that, when assessing probabilities, the decision-makers apply a twofold process. First, they anchor their judgmental probability to some value, here the mean of the probability distribution of the election victory for the $L$ party; second, they adjust this anchor value to reflect the ambiguity present in the situation. Because of probability adjustment, it turns out that the sum of the probabilities of the complementary events can be either subadditive (i.e., their sum is less than unity) or superadditive (i.e., their sum is greater than unity): nonadditivity in probabilities reveals individual reaction to uncertainty ${ }^{17}$.

17 This process is also consistent with individual behavior leading to Ellsberg's well-known two-urn paradox; see Ellsberg (1961, pp. 650-653). 
Following Einhorn and Hogarth (1985), we specify the two weights as being

$$
\begin{aligned}
& s\left(p^{L}\right)=p^{L}+\theta\left[\left(1-p^{L}\right)-\left(p^{L}\right)^{\beta}\right], \\
& s\left(1-p^{L}\right)=1-p^{L}+\theta\left[p^{L}-\left(1-p^{L}\right)^{\beta}\right] .
\end{aligned}
$$

As long as inflation is perceived as a loss (i.e., as a negative payoff), we define a decision-maker to be ambiguity-neutral if $s\left(p^{L}\right)=p^{L}$, and to be ambiguity-averse [or -prone] if $s\left(p^{L}\right)>p^{L}$ [or $\left.s\left(p^{L}\right)<p^{L}\right]^{18}$ : ambiguity aversion [proneness] implies that the private sector overestimates [underestimates] the anchor probability of the worst outcome. The parameter $\theta$, with $0 \leq \theta \leq 1$, captures the amount of ambiguity perceived in the situation by the decision-makers, which we shall henceforth call objective ambiguity. In particular, it represents the elevation of the weighting function, namely, the size of the simulated probability values different from the anchor (i.e., the greater the perceived ambiguity, the greater is the size of the simulation). When $\theta=0$, there is no ambiguity. From (5), it follows that $s\left(p^{L}\right)=p^{L}, s\left(1-p^{L}\right)=1-p^{L}$ : complementary probability weights are additive; the decision-makers act as if they were expected-utility maximizers, and (4) is equivalent to rational expectations. When $\theta>0$, the decision-makers do not possess all the information necessary to make a decision. When $\theta=1$, they have no information at all and must make a choice under complete ignorance. Therefore, $0 \leq \theta \leq 1$ captures how ambiguous the event election is for all of the decision-makers.

The parameter $\beta \geq 0$ indicates the private sector's psychological attitude toward ambiguity, namely the curvature of the weighting function, which we shall henceforth call subjective ambiguity. When $\beta=1$, the private sector gives equal weight to adjustments below and above the anchor. When $\beta<1(\beta>1)$, the private sector attaches more weight to adjustments below (above) the anchor. With $p^{L}=1 / 2$, it turns out that $s\left(p^{L}\right)=$ $(1 / 2)\left\{1+\theta\left[1-(1 / 2)^{\beta-1}\right]\right\}=s\left(1-p^{L}\right)$. That is, $\beta=1$ implies $s\left(p^{L}\right)=p^{L}$ or ambiguity neutrality, and $\beta>1(\beta<1)$ implies $s\left(p^{L}\right)>p^{L}\left(s\left(p^{L}\right)<p^{L}\right)$ or ambiguity aversion (proneness) ${ }^{19}$.

Figure 1 plots the weighting function $s\left(p^{L}\right)$ under different assumptions as regards $\beta$, while keeping $\theta>0$ constant.

18 In the case of gains (i.e., positive payoffs), ambiguity aversion implies $s(p)<p$, and proneness $s(p)>p$.

19 In Einhorn and Hogarth (1985), $\beta<1$ [or $\beta>1$ ] implies subadditive [or superadditive] decision weights: $s\left(p^{L}\right)+s\left(1-p^{L}\right)<1\left[\right.$ or $\left.s\left(p^{L}\right)+s\left(1-p^{L}\right)>1\right]$. However, in the current model, the equivalence between subadditivity [superadditivity] of the decision weights and ambiguity proneness [aversion] in the case of losses is not necessarily valid when the value of the anchor probability differs from $p=1 / 2$. 


\section{Figure 1}

Different Weighting Functions $S(p)$ that are Determined by Differences in the Individual Values of $\beta$, while Keeping Constant the Level of Objective Uncertainty $\theta>0$

$$
S(p)=1
$$

$S(p)=$ weighting function

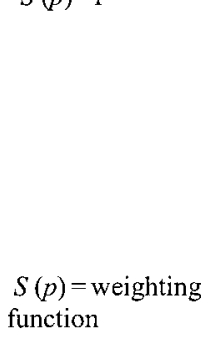

$S(p)=0$

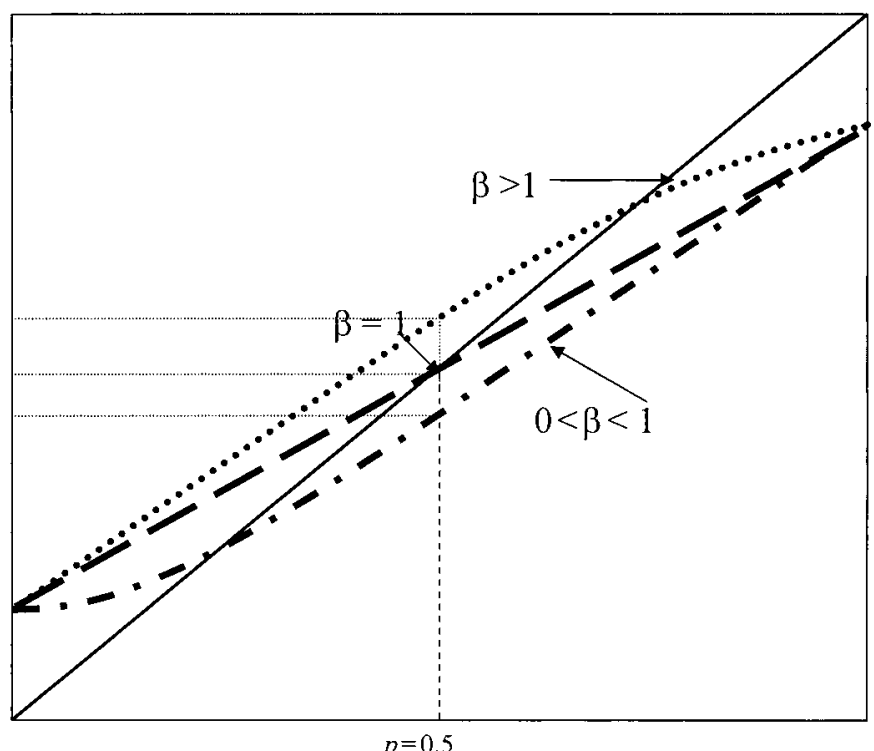

$$
p=0
$$

$$
p=\text { probability }
$$

These features of the model imply that the $k$ decision-makers will expect more (less) inflation than the ambiguity-neutral residual fraction, $1-k$, when they are ambiguity-averse (-prone).

Using (4) and (5), it follows that the expected inflation rate for $t=1$, formed before the election takes place, and that for $t=2$, formed after it has taken place, are, respectively,

$$
\begin{array}{ll}
\Pi_{1}^{E}=(1-k)\left[\frac{\Pi^{R}+\Pi^{L}}{2}\right]+k\left[\frac{\Pi^{R}+\Pi^{L}}{2}\right]\left\{1+\theta\left[1-\left(\frac{1}{2}\right)^{\beta-1}\right]\right\}, \\
\Pi_{2}^{E}=\Pi^{R}+k \theta\left(\Pi^{L}-\Pi^{R}\right) \quad \text { if } R \text { is incumbent, } \\
\Pi_{2}^{E}=\Pi^{L}+k \theta\left(\Pi^{R}-\Pi^{L}\right) \quad \text { if } L \text { is incumbent, }
\end{array}
$$

where we have made use of $\Pi_{1}^{i}=\Pi_{2}^{i}=\Pi^{i}, i=\{L, R\}$, from (3).

Given the private sector's subjective expectations of inflation, we can now derive the unemployment rate in the first period of administration of a newly elected government. By substituting (3) and (6.1) back into (1), the 
postelection deviation of unemployment from its natural rate, if party $R$ wins the election, is

$$
\begin{aligned}
U_{1}^{R}-U^{N} & =a\left(\Pi_{1}^{E}-\Pi_{1}^{R}\right) \\
& =\underbrace{\frac{a^{2}}{4}\left(b^{L}-b^{R}\right)}_{\text {ALESINA EFFECT }}+\underbrace{\frac{a^{2}}{4}\left(b^{L}+b^{R}\right) k \theta\left[1-\left(\frac{1}{2}\right)^{\beta-1}\right]}_{\text {AMBIGUITY EFFECT }} .
\end{aligned}
$$

If instead party $L$ wins, the corresponding postelection deviation is

$$
\begin{aligned}
U_{1}^{L}-U^{N} & =a\left(\Pi_{1}^{E}-\Pi_{1}^{L}\right) \\
& =\underbrace{\frac{a^{2}}{4}\left(b^{R}-b^{L}\right)}_{\text {ALESINA EFFECT }}+\underbrace{\frac{a^{2}}{4}\left(b^{L}+b^{R}\right) k \theta\left[1-\left(\frac{1}{2}\right)^{\beta-1}\right]}_{\text {AMBIGUITY EFFECT }} .
\end{aligned}
$$

When party $R$ (or $L$ ) wins the election, we can decompose the deviation of the actual rate of unemployment from its natural rate into two parts. The first term on the right-hand side of (7.1) (or 7.2) is equivalent to what we would obtain in Alesina (1987); we call it the Alesina effect. The second term on the right-hand side of (7.1) (or 7.2) occurs only if a fraction of the population, $k>0$, is not ambiguity-neutral, here equivalent to $\beta \neq 1$; we call this term the ambiguity effect ${ }^{20}$. Of course, given that $b^{L}>b^{R}>0$, if party $R$ is elected and $k=0$, there is a postelection slump, because the electoral uncertainty has caused expected inflation to be higher than actual inflation. For a positive but sufficiently small value of $k$, the postelection slump is smaller (bigger) when the $k$ decision-makers are ambiguity-prone (-averse). Figure 2 illustrates.

We can explain these results intuitively as follows. If the $k>0$ decision makers are ambiguity-prone (-averse), they tend to underestimate (overestimate) the probability of victory for both parties $L$ and $R$, as long as $s\left(p^{L}\right)=(1 / 2)\left\{1+\theta\left[1-(1 / 2)^{\beta-1}\right]\right\}=s\left(1-p^{L}\right)<1 / 2(>1 / 2)$ for $\beta<1(\beta>1)$ and $p^{L}=1 / 2$. As a consequence, expected inflation is smaller (larger) than for $k=0$, and thus the deflation surprise is also smaller (larger). In other words, "optimism" (that is, ambiguity proneness) on the part of the decisionmakers with respect to the likelihood they assign to their worst election outcome (i.e., that the high-inflation, left-wing party wins the election) is good for postelection employment: optimism induces them to expect less than average postelection inflation, which implies a smaller surprise if the right wins, and thus a smaller slump, or equivalently, a bigger surprise if the left wins, and thus a bigger boom.

20 The ambiguity term in (7.1)-(7.2) depends on the average inflation bias of the two governments, not on partisanship per se: an increase in partisanship that leaves the mean inflation bias unaffected does not change this term. This result depends on assuming both a loss function linear in unemployment and $p^{L}=1 / 2$. 


\section{Figure 2}

Postelection Outcome at $t=1$, when Party $R$ has won the Election and $p^{L}=1 / 2$

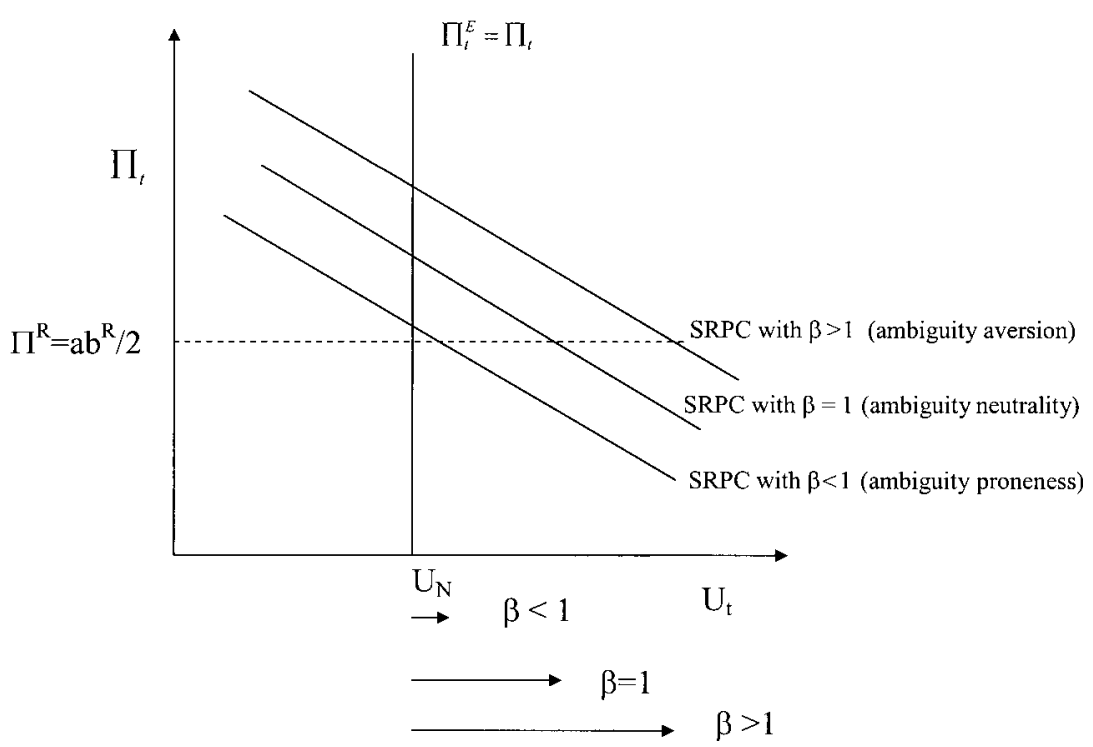

Note: $R=$ party $R$ has won the election; $0 \leq \theta \leq 1$ denotes objective ambiguity; assuming that the probability anchor is $p^{L}=1 / 2$, ambiguity proneness (aversion) implies $k>0$ and $\beta<1(\beta>1)$. SRPC $=$ short-run Phillips curve under different attitudes towards ambiguity.

Alternatively, consider the inflation-policy game as one in which the government's strategy is inflation and the wage-setters' is expected inflation. From (3), the government plays the dominant strategy $\pi^{i}=a b^{i} / 2, i=\{L, R\}$; from (6.1), the wage-setters' best-reply function is $\pi_{i}=c \pi^{E}-\pi_{-i}, c \equiv 2\left\{1+k \theta\left[1-(1 / 2)^{\beta-1}\right]\right\}^{-1}>0$, and $i \neq-i$. The game exhibits strategic complementarities from the wage-setters' viewpoint and negative externalities; with $p^{L}=1 / 2$, ambiguity proneness implies that the wage-setters' best reply has a slope greater than unity. Hence, they will choose a lower strategy by expecting less inflation for a given inflation strategy of the government than in the case of ambiguity-neutral behavior ${ }^{21}$.

21 Diagrammatically, the wage-setters' positively sloped best-reply function becomes steeper (or flatter) in the $\left(\pi^{i}, \pi^{\mathrm{E}}\right)$ space as they become more ambiguity-prone (or ambiguity-averse) in the case of losses. This result is consistent with Eichberger and Kesley's (1999) analysis of the strategic role of uncertainty in two-agent models. 
Turning back to (7.1)-(7.2), if the degrees of objective ambiguity and ambiguity preference are high (i.e., if $\theta$ is close to unity, and - provided $p^{L}=1 / 2-$ if $\beta$ is close to zero, respectively), and if the fraction $k$ of ambiguity-prone decision makers is also high, then it is even possible that the election of party $R$ will give rise to a postelection boom, rather than to a slump. For instance, if we assume $\theta=2 / 3=k$ and $\beta=1 / 2$, then from (7.1) we have a postelection boom when party $R$ wins if $1<b^{L} / b^{R}<1.451265$, i.e., if there are small differences in preferences between parties. The implications of ambiguity for the first period of the partisan business cycle are summarized as follows:

Proposition 1 (Ambiguity and partisan business cycle) Assume that the decision-makers perceive inflation as a loss. Assume also that $p^{L}$ is uniformly distributed, so that the anchor value of the probability is $p^{L}=1 / 2$. For given party preferences $b^{L}>b^{R} \geq 0$ :

1.1. When party $R$ wins the election: (i) if all of the decision-makers are ambiguityneutral, $(k=0)$, there is a postelection Alesina slump; (ii) if a fraction $k>0$ of the decision makers are ambiguity-prone (-averse), then there is a smaller (larger) slump than in Alesina (1987), and the higher the subjective degree of ambiguity proneness (aversion), the smaller (larger) the slump; (iii) if the fraction $k>0$ is sufficiently large, the degree of ambiguity proneness is sufficiently high $(\beta \rightarrow 0)$, and the degree of objective ambiguity is also high $(\theta \rightarrow 1)$, then there can be a postelection boom, provided that the difference between the parties' preferences $b^{L}, b^{R}$ is sufficiently small.

1.2. When party $L$ wins the election: (i) if all of the decision-makers are ambiguityneutral $(k=0)$, there is a postelection Alesina boom; (ii) if a fraction $k>0$ of the decision-makers is ambiguity-prone (-averse), then there is a larger (smaller) boom than in Alesina (1987), and the higher the subjective degree of ambiguity proneness (aversion), the larger (smaller) the boom.

Proof. Directly from (7.1) and (7.2).

We consider next the implications of ambiguity for the time series of unemployment. After the election has occurred, if party $R$ is in power, the decision-makers revise their probability anchor downward to $p^{L}=0$. Using (6.2) in (1), the deviation of unemployment from its natural rate in period $t=2$ is

$$
U_{2}^{R}-U^{N}=a\left(\Pi_{2}^{E}-\Pi_{2}^{R}\right)=\left(\frac{a^{2}}{2}\right) k \theta\left[b^{L}-b^{R}\right] \geq 0 .
$$

If party $L$ is in power, the decision-makers revise their probability anchor upward to $p^{L}=1$. Using (6.3) in (1), the corresponding deviation in 
period $t=2$ is

$$
U_{2}^{L}-U^{N}=a\left(\Pi_{2}^{E}-\Pi_{2}^{L}\right)=\left(\frac{a^{2}}{2}\right) k \theta\left[b^{R}-b^{L}\right] \leq 0 .
$$

From (8.1) [and (8.2)], if objective ambiguity has not disappeared after the election $(\theta>0)$, then inflation is still lower [or higher] than expected: there is a slump [boom] when party $R[L]$ is in power, as long as $b^{L}>b^{R}$. The reason is that the $k$ decision-makers who are not ambiguity-neutral are unsure that the incumbent party will implement its time-consistent inflation policy: they assign some positive probability weight to the outcome that the inflation policy of the defeated party will be implemented instead; see (6.2) for $R$ $[(6.3) \text { for } L]^{22}$. However, if objective ambiguity has disappeared after the election $(\theta=0)$, unemployment will return to its natural rate, with a secondperiod recovery [recession] if party $R[L]$ is in power.

In which situations is it more likely that objective ambiguity will not disappear after the election? We argue that this may be the case for a coalition government, or when the party gains power after a long spell in opposition, or when the party is actually new or has a new, reforming leadership, or when the situation is such that the decision-makers act as if they assigned a positive probability to the occurrence of a sudden and unforeseen event, like the resignation of a political leader following a scandal, the leader's death, or a war. In all of these cases, the reputation of the government for being able to implement its policy, equation (3), can be weak, and objective ambiguity $\theta>0$ can persist. It is in these situations that (8.1) and (8.2) will be more pertinent. Moreover, note that small degrees of objective ambiguity, or a small fraction of non-ambiguity-neutral decision-makers, will generate small deviations of unemployment from its natural rate in the second period. An example of the time series of unemployment for party $R$ under ambiguity proneness (thick lines) and under Alesina (1987) (dot-dash lines) is depicted in Figure 3.

These results are summarized in the following

Proposition 2 (Unemployment persistence) Assume that, after the election, the probability anchor is revised upward (downward) to unity (zero) if party $L(R)$ wins. Then, for given party preferences $b^{L}>b^{R} \geq 0$ :

2.1. If objective ambiguity has disappeared after the election $(\theta=0)$, unemployment will return to its natural rate.

2.2. If objective ambiguity has not disappeared after the election $(0<\theta<1)$, unemployment can permanently deviate from its natural rate. There will be a slump

22 This is our interpretation of the claim that "...the direction of adjustment must be due in part to the value of [the anchor]. Indeed, when [the anchor] equals zero...the adjustment, if there is one, must be upward; when [the anchor] equals one, the adjustment must be downward" (Einhorn and Hogarth, 1985, p. 436). 


\section{Figure 3}

Ambiguity and the Political Business Cycle when Party $R$ is in Office

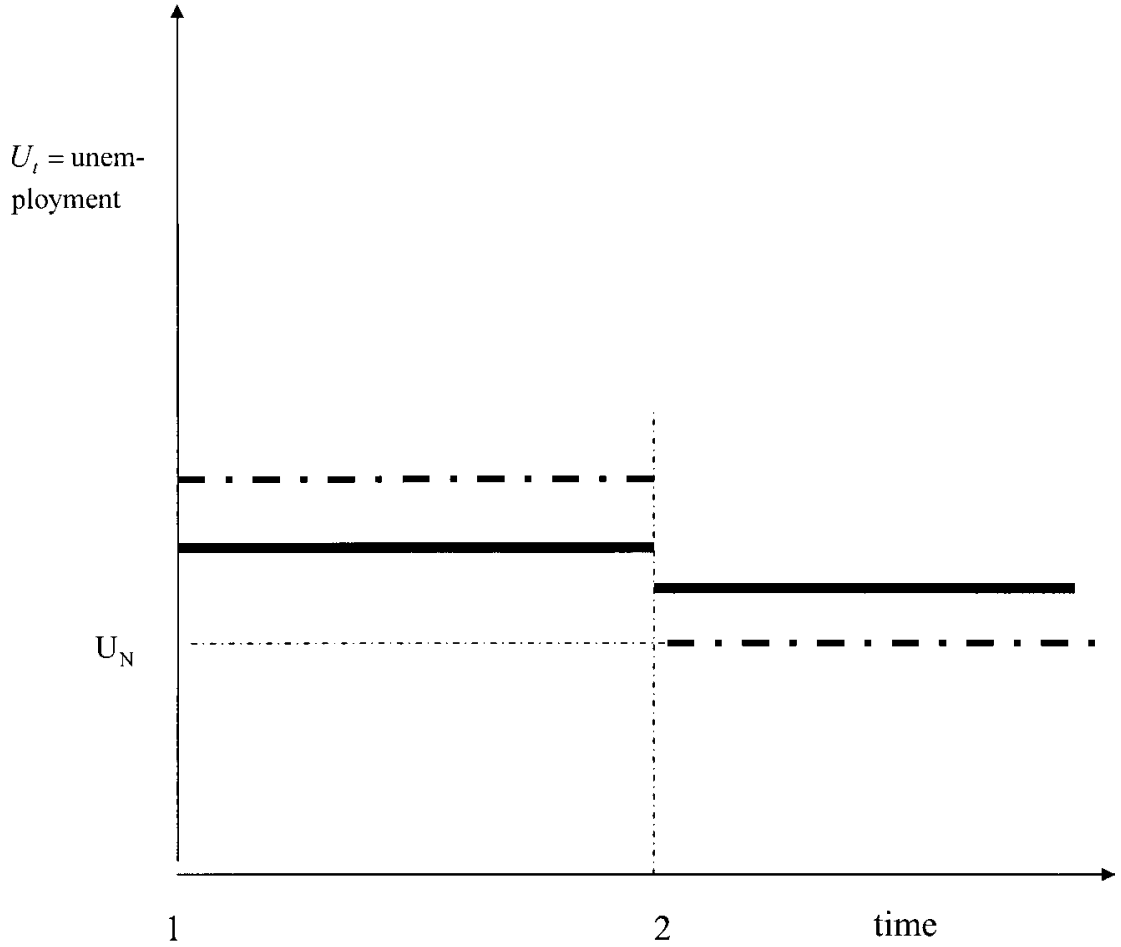

Note: $R$ = party $R$ has won the election. $1=$ first period of tenure; $2=$ second period of tenure. Dash-dot lines: time series of unemployment under Alesina (1987). Thick lines: time series under ambiguity proneness and persistence of objective ambiguity after the election.

(boom) when party $R(L)$ is in office, which implies persistence in the time series of unemployment for $k>0$. Small degrees of objective ambiguity (small values of $\theta$ ) will cause small deviations of the actual rate of unemployment from its natural rate.

Proof. Directly from (8.1)-(8.3).

\section{Ambiguity and Preference Convergence}

The main result of the rational partisan theory is that the election of party $R(L)$ generates lower (higher) than expected inflation, and thus a postelection slump (boom), when the decision-makers have rational expectations. 
However, if the time-consistent inflation policies of the two parties were the same, the private sector would have perfect foresight, and unemployment would never deviate from its natural rate. Therefore, the rational partisan theory predicts that the political business cycle completely disappears when the parties' preferences converge to a common value, i.e., $b^{L} \rightarrow b^{R}=b>0$.

In the introduction, we have argued that convergence in objectives between the new free-market left and the liberal right seems to have been occurring, especially in Europe, during the 1990s. The predictions of our model for this case are summarized in the following

Proposition 3 (Preference convergence) Assume that the relative preferences for inflation and unemployment of parties $L$ and $R$ converge to a common value, i.e., $b^{L} \rightarrow b^{R}=b>0$. Then, provided that the anchor probability value is $p^{L}=1 / 2$, and that, with objective ambiguity $\theta>0$, a fraction $k>0$ of the population is ambiguity-prone (-averse):

3.1. (i) There is a postelection boom (slump); (ii) the deviation from the natural rate of unemployment is the smaller, the smaller is the common-policy time-consistent inflation rate, the smaller is the fraction of ambiguity-prone (-averse) decisionmakers, and the smaller is the amount of objective ambiguity.

3.2. After the postelection boom (slump), unemployment will return to its natural rate.

Proof. 3.1 (i): Using either (7.1) or (7.2), it follows that

$$
\lim _{b^{L} \rightarrow b^{R}=b} U_{1}-U^{N}=\left(\frac{a^{2}}{2} b\right) k \theta\left[1-\left(\frac{1}{2}\right)^{\beta-1}\right],
$$

whose sign is negative (positive) for $\beta<1(\beta>1)$. (ii) follows by direct inspection of the expression above, noting that the common-policy time-consistent inflation rate is given by the first factor in parentheses.

$$
\text { 3.2: Using (8.1) or (8.2), we have } \lim _{b^{L} \rightarrow b^{R}=b} U_{2}-U^{N}=0 \text {. }
$$

If a fraction $k>0$ of wage-setters is ambiguity-prone (-averse), our model predicts that the political business cycle will not disappear, provided that $\theta>0$. The intuitive explanation is similar to that given for Proposition 2: if - notwithstanding preference convergence - objective ambiguity does not disappear, say because the wage-setters assign a positive probability to the occurrence of a sudden and unforeseen event, then the ambiguity-prone (-averse) decision-makers adjust downward (upward) the probability of victory for any party, implying they will expect lower (higher) than average inflation. Before the election, they will set a too low (high) nominal wage rate for the next period: regardless of which party will be in power, the actual postelection inflation rate will lower (raise) the real wage, and unemployment will be reduced (increased). 
Note that our interpretation of the role of ambiguity in Propositions 2 and 3 above allows us to draw a parallel between our approach and the literature on Downsian party competition where voters face a risky choice, being uncertain about the two parties' location along a one-dimensional policy space ${ }^{23}$. This approach, stemming from Downs (1957, p. 136) and Shepsle (1972), and more recently adopted by Alesina and Cukierman (1990), considers the incentives of candidates to purposely behaving "as equivocally as possible about their stands," depending on both the risk attitude of voters and the candidates' objectives. In this literature, there is a risky environment because voters are imperfectly informed about the preferences of politicians, and the risky party is represented as a random variable with a known probability distribution ${ }^{24}$.

In the current model, lack of information as well as conflicting information implies that, although politicians may state unequivocally the same preferences about inflation and unemployment before the election, wage-setters may still perceive uncertainty about the electoral outcome (say, they can neither rule out nor assign a precise probability to the event "inflationary financing of a war by the newly elected government"), and thus about the inflation policy being implemented after the election. In other words, the persistence of uncertainty about the electoral outcome implies that the individual perception of the likelihood of the universal event is not equal to the likelihood attached to the victory of the right plus that of the left. As a consequence, the decision-makers do not assign probability equal to one to the common time-consistent inflation rate, that is, to the common outcome in the case of victory for either party. It is the mere presence of electoral uncertainty that causes a political business cycle, even with full preference convergence ${ }^{25}$.

However, note that small deviations from ambiguity neutrality generate small postelection deviations from the natural rate of unemployment. Finally, note that, when the anchor $p^{R}=1 / 2$, the experimental evidence suggests that most of the subjects are ambiguity-neutral; see Camerer and Weber (1992). Under the assumptions of our model, this would imply a small value of $k$ and a small ambiguity effect, ceteris paribus. However, with a nonuniform probability distribution, non-ambiguity-neutral behavior has been found to

23 We thank an anonymous referee for having alerted us to this. Note that "uncertainty" and "ambiguity" are synonyms for risk in this literature; see Shepsle (1972, footnote 25, p. 559) for a discussion, and footnote 5 above.

24 Enelow and Hinich (1981) see the source of voters' uncertainty not only in the candidates' unknown position, but also in the voters' process of simplifying the candidates' position along the left-right dimension with a shorthand label (such as "right," "center," "left").

25 This is equivalent to saying that the axiom of independence of irrelevant alternatives may be violated. 
be prevalent; see, e.g., Di Mauro and Maffioletti (1996). In such a case, we can anticipate that the size of the ambiguity effects will not be trivial according to our model ${ }^{26}$.

\subsection{Central-Bank Independence}

Alesina and Gatti (1995, p. 199) show that an independent and inflationaverse central bank, which is jointly appointed by the parties before the election, can eliminate output variability arising from electoral uncertainty, and can reduce average inflation. That is, with rational expectations, convergence in objectives, $b^{L} \rightarrow b^{R}=b$, is a perfect substitute for the appointment of an independent central bank with preference parameter $\hat{b}<b$, at least for disposing of the political business cycle. However, if $k>0$ and $\beta \neq 1$, our model puts forward a stronger case for central-bank independence: even if the central bank had the same preference for inflation as the political parties, the higher is its independence from political pressures, the lower is the degree of objective ambiguity $\theta$, and the smaller is the postelection boom or slump. Now, it is well known that central-bank independence can be measured by several institutional characteristics, such as the length of term in office for bank governors, the degree of partisan political influence in decision-making, and the central banker's preference with regard to inflation, or its "degree of conservatism." Our model suggests that objective ambiguity, and thus fluctuations in unemployment, can disappear $(\theta \rightarrow 0)$ if the decision-makers perceive central-bank independence as a stable and permanent feature of monetary policymaking. Institutional arrangements (e.g., constitutional laws establishing the central bank's objectives and instruments; long term lengths for the governors) that insulate monetary policy from short-run political pressures would help to eliminate the political business cycle: convergence in objectives may not be sufficient for this purpose.

\subsection{Ambiguity and the Timing of Contract Negotiation}

One major problem with Alesina's (1987) approach is that the results of a political business cycle depend on wage-setters signing contracts before an election whose timing is fully known. As Garfinkel and Glazer (1994, p. 169) put it, "why should rational, forward-looking decision agents lock themselves into nominal contracts before the resolution of electoral uncertainty ... insofar as elections are predictable events" rather than postponing

26 In an appendix, available on request from the authors, we assume that the expected value of the probability distribution is different from one-half. Using restrictions that are consistent with the existing experimental evidence, we can predict nontrivial ambiguity effects. 
contract negotiations until after the elections? Garfinkel and Glazer (1994) present U.S. evidence in favor of this hypothesis.

We observe that different attitudes towards ambiguity on the part of the decision-makers may explain why some trade unions may prefer not to postpone, whereas other trade unions may prefer to postpone, contract negotiations until after the elections. If the trade unions are ambiguity-loving, they will prefer signing contracts before the election (i.e., taking the uncertain gamble) to waiting for the resolution of electoral uncertainty. However, if they are ambiguity-averse, they may prefer waiting until the uncertainty is resolved (i.e., not taking the gamble). In terms of our model, the endogenous timing of negotiation is still consistent with the idea that electoral uncertainty may generate a political business cycle, provided that the proportion of ambiguity-loving decision-makers is sufficiently large.

\section{Conclusion}

This paper has introduced nonrational decision-makers into a stripped-down version of Alesina's (1987) two-party model of the political business cycle. In the current model, the decision-makers perceive inflation as a loss, and the lack of information or conflicting information about the probability of election victory for one of the two parties can generate electoral ambiguity. Following Einhorn and Hogarth (1985), the decision-makers react to this uncertainty by using decision weights, rather than subjective probabilities, in order to form their estimates of the likelihood of victory for one party. The decision weights are centered on a probability anchor equal to one-half from a unitary uniform distribution. This approach to ambiguity includes rational expectations as a special case.

The paper has shown that, even in the presence of full convergence in objectives, there is the possibility of a postelection boom (slump) when the decision-makers are ambiguity-prone (-averse), provided that there is still ambiguity as regards the election results. In addition, if there are partisan differences among politicians, the paper shows that the subjective perception of ambiguity can change the size and the sign of the political business cycle. For example, if some decision-makers are ambiguity-prone (i.e., $\beta<1$ here), the model predicts a smaller postelection slump than in Alesina when the low-inflation, right-wing party wins the election. However, if the fraction of the ambiguity-prone subjects is sufficiently large (i.e., if $k$ is large here), the victory of the right could generate a boom. This special case is potentially interesting insofar as it differentiates the predictions of the model from Alesina (1987) and Hibbs (1977), where postelection booms occur only when the left gains power: this model can predict situations that are explained 
neither by the partisan model nor by Nordhaus's (1975) opportunistic model (predicting postelection slumps).

The next step is trying to test the predictions of the model empirically. Firstly, we would like to understand whether or not wage-setters react to uncertainty. In a series of experiments (some of which are reported in Maffioletti and Santoni, 2000) designed to elicit ambiguity preference in a sample of Italian trade-union delegates and leaders, we find some evidence of ambiguity reaction, especially when wage-setters are facing real, as opposed to fictitious, uncertainty. Second, we would like to find some direct evidence of an ambiguity effect in macroeconomic data. The experimental literature finds that subjects exhibit ambiguity reaction for extreme values of the probability anchor; see Camerer and Weber (1992). This seems to suggest that one place to look for evidence of an ambiguity effect would be in postelection economies for which either election defeats or landslides were widely forecast. One problem, however, is how to measure empirically the degree of ambiguity involved in these situations (namely the degree of objective ambiguity $\theta$ ). We shall leave this task for future work.

\section{References}

Alesina, A. (1987), Macroeconomic Policy in a Two-Party System as a Repeated Game, Quarterly Journal of Economics 102, 651-678.

Alesina, A., and A. Cukierman (1990), The Politics of Ambiguity, Quarterly Journal of Economics 105, 829-850.

Alesina, A., and R. Gatti (1995), Independent Central Banks: Low Inflation at No Cost?, American Economic Review (Papers and Proceedings) 85, 196-200.

Alesina, A., N. Roubini and G. Cohen (1997), Political Cycles and the Macroeconomy, Cambridge, Massachusetts.

Alogouskofis, G. S., B. Lockwood and A. Philippopoulos (1992), Wage Inflation, Electoral Uncertainty and the Exchange Rate Regime: Theory and UK Evidence, Economic Journal 102, 1370-1394.

Bohm, P., and J. Sonnegard (1999), Political Stock Markets and Unreliable Polls, Scandinavian Journal of Economics 101, 205-222.

Camerer, C., and M. Weber (1992), Recent Developments in Modelling Preferences: Uncertainty and Ambiguity, Journal of Risk and Uncertainty 5, 325-370.

Chiarini, B. (1999), The Composition of Union Membership: The Role of Pensioners in Italy, British Journal of Industrial Relations 37, 577-600.

Cukierman, A., and F. Lippi (1999), Central Bank Independence, Centralization of Wage Bargaining, Inflation and Unemployment: Theory and Some Evidence, European Economic Review 43, 1395-1434.

Di Mauro, C., and A. Maffioletti (1996), An Experimental Investigation of the Impact of Ambiguity on the Valuation of Self-Insurance and Self-Protection, Journal of Risk and Uncertainty 13, 53-71.

Di Tella, R., R. J. MacCulloch and A. J. Oswald (2001), Preferences over Inflation and Unemployment: Evidence from Survey of Happiness, American Economic Review 91, 335-341. 
Downs, A. (1957), An economic theory of democracy, New York.

Drazen, A. (2000), Political Economy in Macroeconomics, Princeton, New Jersey.

Eichberger, J., and D. Kesley (1999), Uncertainty and Strategic Interaction in Economics, mimeo, University of Birmingham.

Einhorn, H. J., and R. M. Hogarth (1985), Ambiguity and Uncertainty in Probabilistic Inference, Psychological Review 92, 433-461.

Ellsberg, D. (1961), Risk, Ambiguity and the Savage Axioms, Quarterly Journal of Economics 75, 643-669.

Enelow, J., and M. J. Hinich (1981), A New Approach to Voter Uncertainty in the Downsian Spatial Model, American Journal of Political Science 25, 483-493.

Garfinkel, M., and A. Glazer (1994), Does Electoral Uncertainty Cause Economic Fluctuations, American Economic Review (Papers and Proceedings) 84, 169-173.

Grüner, H. P., and C. Hefeker (1999), How Will EMU Affect Inflation and Unemployment in Europe, Scandinavian Journal of Economics 101, 33-47.

Hibbs, D. (1977), Political Parties and Macroeconomic Policy, American Political Science Review 71, 1467-1487.

Hogarth, R. M., and H. J. Einhorn (1990), Venture Theory: A Model of Decision Weights, Management Science 36, 780-803.

Jonsson, G. (1997), Monetary policy and unemployment persistence, Journal of Monetary Economics 39, 303-325.

Jowell, R. et al. (1993), The 1992 British Election: The Failure of the Polls, Public Opinion Quarterly 57, 238-263.

Maffioletti, A., and M. Santoni (2000), Do Trade Union Leaders Exhibit Ambiguity Reaction?, Rivista Internazionale di Scienze Sociali CVIII, 357-376.

Nordhaus, W. (1975), The Political Business Cycle, Review of Economic Studies 42, 169-190.

Persson, T., and G. Tabellini (1999), Political Economics and Macroeconomic Policy, in J.B. Taylor and M. Woodford (eds.), Handbook of Macroeconomics, Amsterdam, vol 1c, ch.22.

Schmeidler, D. (1989), Subjective Probability and Expected Utility without Additivity, Econometrica 57, 571-587.

Shepsle, K. A. (1972), The Strategy of Ambiguity: Uncertainty and Electoral Competition, American Political Science Review 66, 555-568.

Shiller, R. J. (1996), Why Do People Dislike Inflation?, in C. Romer and D. Romer (eds.), Reducing Inflation: Motivation and Strategies, Chicago, 25-117.

Tversky, A., and C. Fox (1995), Weighing Risk and Uncertainty, Psychological Review 102, 269-283.

Tversky, A., and D. Kahneman (1992), Advances in Prospect Theory: Cumulative Representation of Uncertainty, Journal of Risk and Uncertainty 5, 297-323.

Tversky, A., and P. Wakker (1995), Risk Attitudes and Decision Weights, Econometrica $63,1255-1280$.

Wu, G., and R. Gonzalez (1999), Non-Linear Decision Weights in Choice under Uncertainty, Management Science 45, 74-85.

\section{Anna Maffioletti}

Dipartimento di Economia

Università degli Studi di Torino

Via Po 53

10124 Torino (TO)

Italy

anna.maffioletti@unito.it

\author{
Michele Santoni \\ DEPA, Facoltà di Scienze Politiche \\ Università degli Studi di Milano \\ Via Conservatorio 7 \\ 20122 Milano (MI) \\ Italy \\ michele.santoni@unimi.it
}

